\title{
Coping with rational prodigals: A Theory of Social Security and Savings Subsidies
}

\author{
By Stefan Homburg \\ DISCUSSION PAPER NO. 293 \\ JANUARY 2004 \\ ISSN: 0949-9962
}

\begin{abstract}
School of Economics and Management, University of Hannover, Königsworther Platz 1, D-30167 Hannover, Germany. www.fiwi.uni-hannover.de.
\end{abstract}

\begin{abstract}
The rational prodigality argument, which often serves to justify social security, is considered in a second-best tax framework with endogenous labor supply. Rational prodigality renders the familiar policies time inconsistent. We analyze time consistent policies and show that a wage tax suffices to rule out prodigality as a rational strategy. However, using savings subsidies, the solution can be improved upon. The subsidies are shown to be decreasing in income. A social security system with increasing contributions is needed in neither case.
\end{abstract}

Revised version published in:

Economica 73 (2006), pp. 47 ff.

KEYwORDS: Social Security, Pensions, Subsidies, Optimal Taxation.

JEL-CLASSIFICATION: H2, H55 


\section{INTRODUCTION ${ }^{1}$}

Among the efficiency theories of social security (Mulligan and Sala-i-Martin, 1999), rational prodigality plays a prominent role. This term characterizes a moral hazard problem where people who are in a position to provide for retirement do not do so, but instead speculate on public welfare when old. With exogenous earnings, there is a first-best remedy - one simply forces the young to save. Hayek (1960, p. 286) was among the first to point out that the rationale of social security "is not that people should be coerced to do what is in their individual interest but that, by neglecting to make provision, they would become a charge to the public. ... Up to this point the justification for the whole apparatus of 'social security' can probably be accepted by the most consistent defenders of liberty."

However, this traditional argument seems to miss the point. With endogenous earnings, the matter appears less clear-cut, because forcing a rational prodigal to save reduces his utility and changes incentives, and it is by no means clear whether such a measure improves the allocation. The theory of second-best taxation holds that distorting economic decisions is generally optimal, and even extreme inefficiencies such as unemployment of productive individuals - the famous bunching at the bottom - can be optimal under asymmetric information.

The present paper offers a rigorous treatment of the rational prodigality problem in a model of second-best taxation which takes into account the interaction of decisions to save and decisions to work $^{2}$. We are particularly interested in the instruments the government may use to cope with rational prodigals. Before starting, it should be emphasized that the paper is not concerned with pay-as-you-go versus fully funded pension systems, but with the deeper question of whether or not compulsory retirement provisions can be justified at all.

\section{THE MODEL}

Consider an economy with a given interest factor $R>0$ and given wage rates per hour, ordered in the form $w^{0}<w^{1}<\ldots<w^{H}(H \geq 1)$. We assume $w^{0}=0$, which will ensure that there are always some unemployed persons. This premise is not important but yields a number of semantic simplifications. People have different unobservable skills, expressed by their wage rates, and choose triples $\left(c_{1}^{h}, c_{2}^{h}, y^{h}\right)$ of first-period consumption, second-period consumption and first-period wage income from their consumption sets $\mathcal{C}^{h}=\mathfrak{R}_{0+}^{2} \times\left[0, \hat{y}^{h}\right]$, where $\hat{y}^{h}>0$ equals the respective wage rate times a uniform constant. With time-separable preferences, the familiar second-best optimum solves

1 I wish to thank two anonymous referees for constructive criticism.

2 There is a second strand in the literature, which portrays the rational prodigality problem as an interaction between altruistic agents, see Lindbeck and Weibull (1986) or Coate (1995). The course followed here is to consider the problem in an optimal taxation framework. 


$$
\max _{\left(c_{1}^{h}, c_{2}^{h}, y^{h}\right) \in e^{h} \text { all } h} \quad W=\sum_{h=0}^{H}\left(u\left(c_{1}^{h}, c_{2}^{h}\right)+v\left(y^{h} / w^{h}\right)\right) f^{h}
$$

$$
\begin{array}{ll}
\text { s.t. i) } & \sum_{h=0}^{H}\left(y^{h}-c_{1}^{h}-c_{2}^{h} / R\right) f^{h} \geq g, \\
& \text { ii) } u\left(c_{1}^{k}, c_{2}^{k}\right)+v\left(y^{k} / w^{k}\right) \geq u\left(c_{1}^{h}, c_{2}^{h}\right)+v\left(y^{h} / w^{k}\right) \text { for all } k \text { and } h,
\end{array}
$$

where the numbers $f^{h}$ denote the fractions of people with skill level $w^{h}$. The exogenous revenue requirement $g$ is assumed to be small enough to allow strictly positive consumptions of all persons at the optimum ${ }^{3}$. Restriction i) represents the government's budget constraint, while ii) comprises the self-selection constraints: At an optimum, it must be impossible for every person $k$ to profit from mimicking some person $h$. The functions $u$ (strictly monotonically increasing) and $v$ (strictly monotonically decreasing) are continuous and strictly concave on their respective domains and smooth at least in the interiors. Beside these technical requirements, we assume that second-period consumption is a (strictly) normal good. The intertemporal marginal rate of substitution equals $\operatorname{mrs}\left(c_{1}^{h}, c_{2}^{h}\right)=u_{1}\left(c_{1}^{h}, c_{2}^{h}\right) / u_{2}\left(c_{1}^{h}, c_{2}^{h}\right)$, where subscripts denote partial derivatives.

At first sight, the problem seems to be difficult to solve because the model contains three commodities, and the famous "single crossing property", which is the principal tool in analyzing the second-best, has no obvious meaning in the presence of more than two commodities (Matthews and Moore 1987). Therefore, we do not know much about the solutions of such models, but in the appendix it is shown that second-best optima are production efficient in the sense that the government's budget constraint holds with equality.

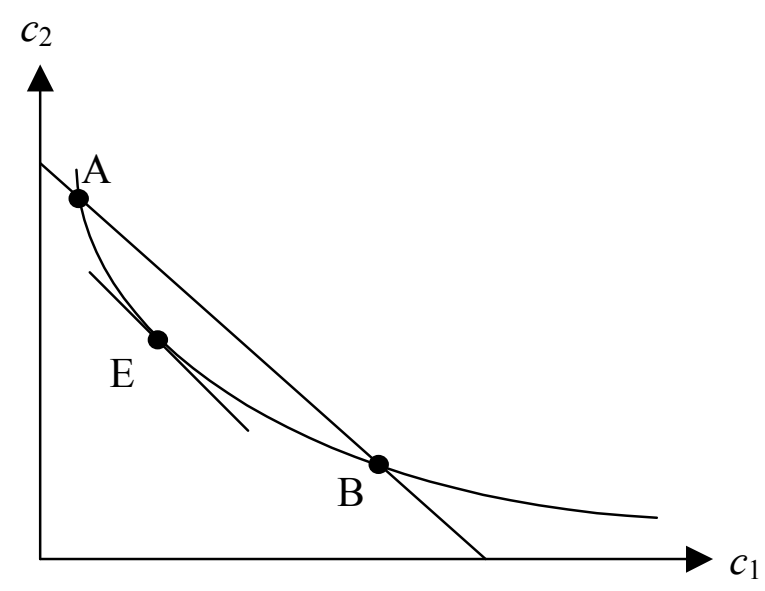

FIGURE 1 - Intertemporal Choices.

Given production efficiency, it is easily seen that intertemporal choices are left undistorted at a second-best optimum, implying $\operatorname{mrs}\left(c_{1}^{h}, c_{2}^{h}\right)=R$ for all $h$. Consider Figure 1, where the straight lines represent intertemporal production possibilities. Moving from points A or B to point $\mathrm{E}$ leaves utility unchanged, preserves all self-selection constraints (because preferences are time-separable) and induces a budget surplus which can be used to increase the social objective. Hence, neither A nor B can be optimal. The intuition is that distorting intertemporal

3 With $g$ small enough, second-best optima surely exist, because we maximize a continuous function over a closed non-empty subset of a compact set. 
choices induces an excess burden without affecting the self-selection constraints (see Diamond 2003, p. 24) $)^{4}$.

Undistorted intertemporal choices allow defining a Hicksian composite $c=c_{1}+c_{2} / R$, where $c_{1}$ and $c_{2}$ are chosen such that $\operatorname{mrs}\left(c_{1}, c_{2}\right)=R$. Using the composite reduces the economy to an economy with just two commodities, so that all results known from the atemporal model (Homburg 2001) apply. In particular, every second-best optimum can be supported by a distortionary wage tax $T\left(y^{h}\right)$ plus private savings $s^{h}$, such that each person solves

$$
\begin{aligned}
& \max _{\left(c_{1}^{h}, c_{2}^{h}, y^{h}\right) \in \mathcal{C}^{h}} \quad u\left(c_{1}^{h}, c_{2}^{h}\right)+v\left(y^{h} / w^{h}\right) \\
& \text { s.t. } \quad \text { i) } \quad c_{1}^{h}+s^{h} \leq y^{h}-T\left(y^{h}\right), \\
& \quad \text { ii) } \quad c_{2}^{h} \leq R s^{h} .
\end{aligned}
$$

This brief exposition elucidates that the standard approach to second-best taxation is not helpful for discussing rational prodigality: When solving (2), nobody will find it optimal not to provide for retirement, which is due to an important hidden assumption: The government can credibly threaten individuals to starve in their old-age if they do not save enough. Such a premise is particularly questionable in the case of the unemployed, who obtain their entire life-time transfer $-T(0)$ in the first period and are expected to save the intended portion for retirement. What, if they do not?

\section{A Simple Time Consistent Policy}

The present approach is based on the observation that modern societies wish to provide a certain minimum standard of living for the elderly, irrespective of prior misconduct. Such an observation is very realistic - and not only for good old Europe. It entails that all older persons are guaranteed one and the same minimum income $c_{2}^{0}$, i. e. the old-age consumption intended for the unemployed. In what follows, the magnitude of the minimum income is not assumed ad hoc but is determined perfectly endogenously.

Regarding the unemployed, an income guarantee raises no problem: The government pays a portion $-T(0)=c_{1}^{0}$ to the young and a portion $c_{2}^{0}$ to the old, so that the unemployed obtain the intended transfer payments in each period and are not expected to save. However, the prospect of a guaranteed retirement income can induce young workers to behave as rational prodigals, meaning that they consume their entire disposable income when young and rely on public welfare when old. In order to rule out such a behavior, a time consistent policy takes into account, for each worker, the incentive compatibility constraint

$$
u\left(c_{1}^{h}, c_{2}^{h}\right) \geq u\left(c_{1}^{h}+c_{2}^{h} / R, c_{2}^{0}\right) .
$$

The left-hand side shows the utility of a worker who accepts the pair $\left(c_{1}^{h}, c_{2}^{h}\right)$ intended for him, whereas the right-hand side shows the utility of a rational prodigal who spends his entire lifetime consumption during his youth (by choosing $s^{h}=0$ ) and obtains the second-period

4 The premise of additive separability could be relaxed by assuming a weakly separable utility function $u\left(U\left(c_{1}, c_{2}\right), y / w\right)$ instead. This entails also that intertemporal distortions leave labour supply unaffected. 
transfer intended for the unemployed after retirement. Note that prodigality will always increase lifetime consumption by $c_{2}^{0} / R$, but will not always increase lifetime utility.

Now, a time consistent policy maximizes W subject to the restrictions in (1) and subject to the additional restriction (3), whereas the time inconsistent policy discussed above neglects that very restriction. From basic principles of optimization it follows that the outcome of the timeconsistent policy is strictly inferior to the outcome of the second-best policy, if the latter violates at least one incentive compatibility constraint. Such a violation is assumed from now on in order to render the problem meaningful.

PROPOSITION 1: Every solution of (1) subject to (3) satisfies $m r s\left(c_{1}^{h}, c_{2}^{h}\right)=R$ for all workers and can be supported by a wage tax, where each person solves

$$
\begin{array}{ll}
\max _{\left(c_{1}^{h}, c_{2}^{h}, y^{h}\right) \in \mathcal{C}^{h}} & u\left(c_{1}^{h}, c_{2}^{h}\right)+v\left(y^{h} / w^{h}\right) \\
\text { s.t. } & \text { i) } \quad c_{1}^{h}+s^{h} \leq y^{h}-T\left(y^{h}\right), \\
& \text { ii) } \quad c_{2}^{h} \leq \max \left\{R s^{h} ; c_{2}^{0}\right\}, \\
\text { iii) } \quad s^{h} \geq 0 .
\end{array}
$$

PROOF: Per absurdum, assume that for some worker the government intended a consumption pair such that $\operatorname{mrs}\left(c_{1}^{h}, c_{2}^{h}\right) \neq R$. Moving along $h$ 's indifference curve toward the undistorted bundle leaves all self-selection constraints unaffected and reduces the $\operatorname{costs} c_{1}^{h}+c_{2}^{h} / R$. Moreover, this move slackens the incentive compatibility constraint (3) because it leaves the lefthand side unchanged and reduces the right-hand side. Since optima are production efficient, the reduced costs present a contradiction, proving $\operatorname{mrs}\left(c_{1}^{h}, c_{2}^{h}\right)=R$. Because all workers' intertemporal decisions remain undistorted, the model essentially boils down again to an economy with just two commodities, whose solution can be supported by a wage tax.

The interesting finding here is that a wage tax alone suffices to render rational prodigality impossible - the government does not need additional instruments. The resulting tax schedule takes a different shape, of course, because the incentive compatibility constraints present an additional limit to redistribution. Constraint iii) in (4) says that the government is not ready to repay any debt, implying that $s^{h}<0$ is not a feasible individual strategy.

As a very simple example, consider an economy with uniformly distributed wage rates $w^{0}=0$, $w^{1}=2$ and $w^{2}=8$, an interest factor $R=1$, tax revenue $g=0$, and a logarithmic utility function $\ln c_{1}^{h}+\ln c_{2}^{h}+\ln \left(500-y^{h} / w^{h}\right)$. Table 1 displays the second-best optimum.

\begin{tabular}{ccccccc}
\hline$w$ & $c_{1}$ & $c_{2}$ & $y$ & $u$ & $\hat{u}_{p}$ & $T$ \\
\hline 0 & 368 & 368 & 0 & 18.0 & & -737 \\
2 & 439 & 439 & 296 & 18.0 & 18.6 & -582 \\
8 & 894 & 894 & 3.106 & 18.3 & 18.1 & 1319 \\
$\Sigma$ & & & & 54.4 & & 0 \\
\hline
\end{tabular}

TABLE 1. Second-best Optimum.

From the fact that first-period consumption equals second-period consumption for each person, it follows that intertemporal choices are left undistorted (but the consumption-leisure 
decisions are generally distorted). The policy supporting this optimum is time inconsistent because the utility of behaving as a rational prodigal, denoted as $\hat{u}_{p}$ in the table, exceeds actual utility of the median persons. These would rather spend their entire incomes during their youth and rely on public welfare when old, thereby increasing utility from 18.0 to 18.6.

\begin{tabular}{ccccccc}
\hline$w$ & $c_{1}$ & $c_{2}$ & $y$ & $u$ & $\hat{u}_{p}$ & $T$ \\
\hline 0 & 535 & 230 & 0 & 17.9 & -- & -765 \\
2 & 460 & 460 & 419 & 17.9 & 17.9 & -501 \\
8 & 911 & 911 & 3.089 & 18.4 & 17.7 & 1266 \\
$\Sigma$ & & & & 54.2 & & 0 \\
\hline
\end{tabular}

TABle 2. Time Consistent Wage Tax.

Such an inclination is taken into account by the time consistent policy shown in Table 2, where the median persons are just willing to accept the consumption pairs intended for them. The social objective falls from 54.4 to 54.2. However, one should recognize that there is no Pareto-ordering between the allocations shown in the two tables: The rich are better off in the second case because the incentive compatibility constraint presents an additional impediment to redistribution - it shields the rich from heavy taxation. This outcome is not robust but only an illustration. Due to the complexity of the Mirrlees framework, almost anything can happen if one introduces an additional constraint. The only robust feature of the time-consistent policy is that it yields lower aggregate welfare than the second-best policy.

Before concluding this section, we would like to contrast our results with two related papers: Homburg (2000) restricts the government's toolbox to two linear instruments, namely, a wage tax and a pension scheme. Such a presumption is not unrealistic since many governments contemplate introducing "flat taxes" or have already implemented them, and social security contributions are normally linear anyway. With linear instruments only, second-best optima cannot be supported, and existence of rational prodigals can be optimal. The idea is simple: Assume there existed a rational prodigal being indifferent between his position and the position of the unemployed. Introducing social security makes prodigality less attractive - with the consequence that the former prodigal becomes unemployed. This tightens the government's budget and may result in a Pareto deterioration.

Weizsäcker (2003) considers a government equipped with two full-fledged instruments, a wage tax and a pension scheme, and assumes that, for some reason or another, rational prodigals exist. He shows that the government can eliminate the prodigals by offering them a somewhat higher second-period consumption. This move yields a Pareto-improvement. However, the new allocation is not second-best efficient, because there is no Pareto-ordering between allocations with rational prodigals and second-best allocations. Hence, the policy only wipes out gross inefficiencies assumed to exist from the outset, and does not entail secondbest efficiency. Such a policy is difficult to rationalize because a government that controls two non-linear instruments can implement the second-best, as we shall see. 
Both companion papers do not affect the basic message of this section: Using a wage tax only and diminishing the degree of redistribution suffices to rule out rational prodigals. In the following sections we will show that more ambitious governments can do still better.

\section{Liberal SOlution: SOCIAL SECURITY}

Once a possible problem has been recognized by the public, it does not take long for an expert to show up and to suggest a solution. Liberals are particularly susceptible to the idea that government intervention will cure all sorts of "market failures". And in the present context, the bureaucrats can indeed make an attractive offer, proposing an intervention that facilitates reaching the second-best.

PROPOSITION 2: Every second-best optimum can be supported by a wage tax combined with social security contributions $B\left(y^{h}\right)$ and pensions $R B\left(y^{h}\right)$, where each person solves

$$
\begin{aligned}
& \max _{\left(c^{h}, c_{2}, y^{h}\right) \in e^{h}} u\left(c_{1}^{h}, c_{2}^{h}\right)+v\left(y^{h} / w^{h}\right) \\
& \text { s.t. i) } c_{1}^{h}+s^{h} \leq y^{h}-T\left(y^{h}\right)-B\left(y^{h}\right) \text {, } \\
& \text { ii) } c_{2}^{h} \leq \max \left\{R\left(s^{h}+B\left(y^{h}\right)\right) ; c_{2}^{0}\right\} \\
& \text { iii) } s^{h} \geq 0 \text {. }
\end{aligned}
$$

ProOF: Denote the outcomes of the time inconsistent policy (2) by a bar $\left(^{-}\right)$and set $B\left(\bar{y}^{h}\right)=\bar{s}^{h}$ and $T\left(\bar{y}^{h}\right)=\bar{T}\left(\bar{y}^{h}\right)$ for all $h$. As all incomes and incentives remain unchanged, everybody accepts $\left(\bar{c}_{1}^{h}, \bar{c}_{2}^{h}, \bar{y}^{h}\right)$, choosing the corner solution $s^{h}=0$.

The proof rests on the observation that replacing private savings by compulsory contributions plus actuarially fair pensions has no income or incentive effects, except that it precludes rational prodigality through the non-negativity constraint on savings. This constraint states that pensions cannot be pledged, which is in fact a universal feature of real pension systems. Without such a restriction (Konrad and Wagner 2000), rational prodigals could circumvent social security by choosing $s^{h}=-B\left(y^{h}\right)$, again rendering the solution time inconsistent.

Compared with the wage tax policy outlined above, social security follows a different strategy to deal with the incentive compatibility constraint: Instead of reducing the degree of redistribution, social security diminishes attainable first-period consumption, rendering the constraint (3) void since individuals can no longer reach the pair $\left(c_{1}^{h}+c_{2}^{h} / R, c_{2}^{0}\right)$. As long as pensions are actuarially fair, doing so induces no inefficiencies and makes it possible to support the second-best optimum in a time consistent fashion. The contributions so characterized are increasing in income because second-period consumption is a normal good.

\section{LiberTARIAN SOlution: SAVINGS SUBSIDIES}

Confronted with the preceding findings, a libertarian (provided he accepts the premises of second-best taxation at all) will presumably raise a number of objections. Firstly, proposition 2 does not require contributions to be collected by the government itself - it only says that savings should be made mandatory and thus does not justify erecting a public pension system. Secondly, the suggested solution pushes intervention too far because it obliges all 
persons to conduct all their savings under the government's auspices. Finally, any intervention entails administrative costs, which must be weighed against the improvement of the allocation.

Therefore, a libertarian may ask for a second-best instrument which minimizes administrative costs and maximizes individual freedom. Such an instrument can be constructed as follows: Denote the optimal outcomes of the time inconsistent policy (2) by a bar, and define $t\left(\bar{y}^{h}\right)$ as the smallest non-negative number satisfying $u\left(\bar{c}_{1}^{h}, \bar{c}_{2}^{h}\right) \geq u\left(\bar{c}_{1}^{h}+\bar{c}_{2}^{h} / R-t\left(\bar{y}^{h}\right), \bar{c}_{2}^{0}\right)$ at the secondbest optimum. In case of a violation of the incentive compatbility constraint, we have $u\left(\bar{c}_{1}^{h}, \bar{c}_{2}^{h}\right)<u\left(\bar{c}_{1}^{h}+\bar{c}_{2}^{h} / R, \bar{c}_{2}^{0}\right)$, and since $u\left(\bar{c}_{1}^{h}, \bar{c}_{2}^{h}\right)>u\left(\bar{c}_{1}^{h}, \bar{c}_{2}^{0}\right)$, some such $t\left(\bar{y}^{h}\right)<s^{h}$ must exist. Moreover, the number $t\left(\bar{y}^{h}\right)$ is strictly positive if and only if the incentive compatibility constraint happened to be violated. The following proposition suggests a tax schedule which allows a limited offset of savings against tax liability. In international tax law, such a provision is referred to as an ordinary tax credit; basically, it acts as a savings subsidy. Let us see how it works:

PROPOSITION 3: Every second-best optimum can be supported by a wage tax combined with decreasing savings subsidies, where each person solves (4) and

$$
T\left(\bar{y}^{h}\right)=\bar{T}\left(\bar{y}^{h}\right)+t\left(\bar{y}^{h}\right)-\min \left\{s^{h}, t\left(\bar{y}^{h}\right)\right\} \text { for all } h .
$$

PROOF: Dropping the superscript $h$ and the bar for notational convenience, consider a hypothetical prodigal for whom $t>0$ and $U(c)-u\left(c-t, c_{2}^{0}\right)=0$ holds by hypothesis. Again, $c$ denotes the composite $c_{1}+c_{2} / R$ and $U(c)=u\left(c_{1}, c_{2}\right)$ such that $m r s\left(c_{1}, c_{2}\right)=R$. Being indifferent, the person accepts the bundle intended for him, saves the second-best amount and pays the second-best tax. In order to see that the subsidies are in fact decreasing in income, apply the implicit function theorem to the last equation, using the identity $U^{\prime}(c)=u_{1}\left(c_{1}, c_{2}\right)$ :

$$
\frac{d t}{d c}=\frac{u_{1}\left(c-t, c_{2}^{0}\right)-u_{1}\left(c_{1}, c_{2}\right)}{u_{1}\left(c-t, c_{2}^{0}\right)}
$$

Since $c-t>c_{1}$ and since $u_{1}\left(c_{1}, c_{2}\right)$ decreases in $c_{1}$ along an indifference curve (this is clear for additive utility functions and also true if second-period consumption is a normal good), the numerator is negative and thus $d t / d c<0$. As the self-selection constraints imply that $c$ and $y$ always move in the same direction, $t$ must also be decreasing in $y$.

Figure 2 displays the kinked budget set induced by the time inconsistent policy. The worker under consideration would behave as a rational prodigal $(\mathrm{P})$ rather than save the second-best amount (S). The instrument $t\left(y^{h}\right)$ corresponds to the horizontal distance between points $\mathrm{X}$ and $\mathrm{P}$; it eliminates the shaded rectangle from the budget set and makes the worker willing to accept S. By contrast, the previous instrument $B\left(y^{h}\right)$ corresponds to the horizontal distance between points $\mathrm{S}$ and $\mathrm{P}$; it eliminates all points to the right of $\mathrm{S}$ from the budget set. Compared with social security, savings subsidies interfere less heavily with individual freedom in that a good deal of private savings remains completely unregulated. In particular, the subsidies are likely to be zero for the rich. Where they are positive, they minimize administrative costs, because the savings test can be conducted by the fiscal office during tax assessment. This result may explain why many countries subsidize savings; think of the 401(k) plans or the German "Riester pensions", for instance. 


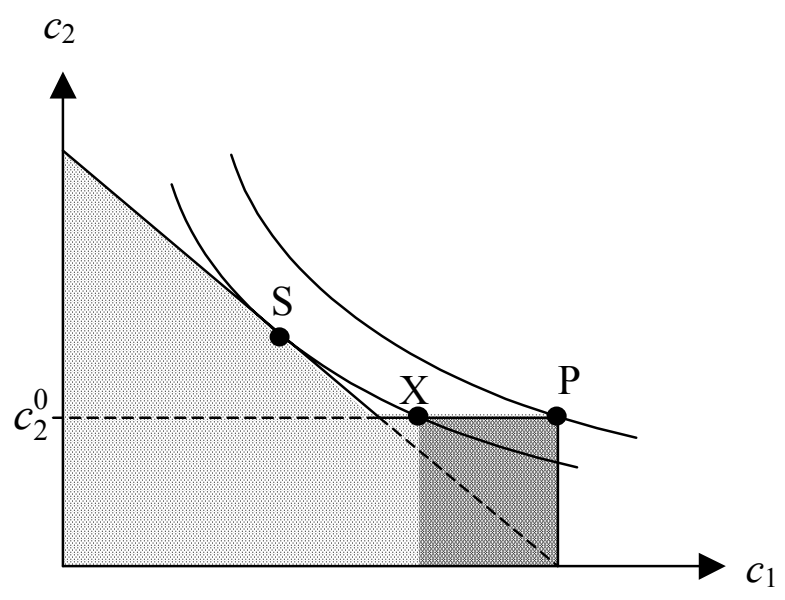

Figure 2 - SeCOND-BEst POLICIES COMPARED.

The savings subsidies are strictly decreasing over the range where they are strictly positive, and vanish for all incomes beyond some threshold (if any). This characteristic shape, illustrated in Figure 3, has a straightforward intuition: Prodigality is less pleasing for the rich, because the rich want to enjoy high second-period consumption. A top manager, when behaving as a rational prodigal, could afford an enormous consumption when young, but only at the price of minimal consumption after retirement. Such a behavior runs counter to the idea of "consumption smoothing" over the life cycle. Therefore, the proposed mechanism is likely to have no subsidies at high income levels. Would-be rational prodigals are probably found at the bottom of the income scale. For them, the hypothetical tax burden is increased. But at the same time, savings are encouraged in that they can be fully offset against the tax liability, up to a certain limit. This induces all persons to save as much as under the time inconsistent policy, with the effect that the actual tax payments remain completely unchanged.

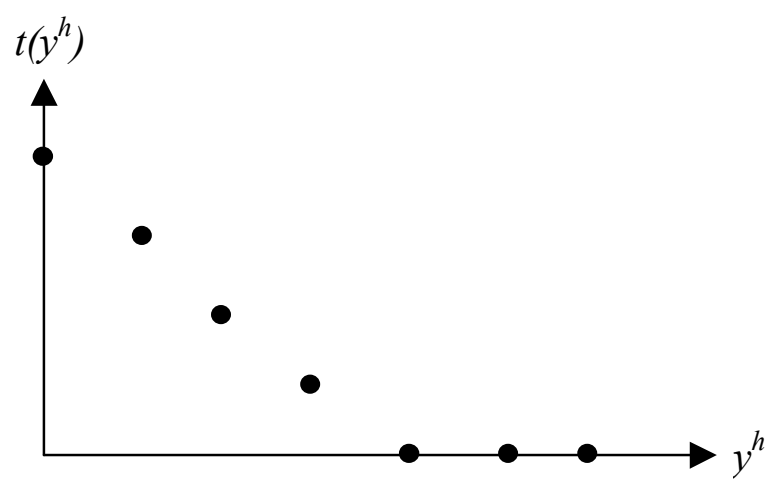

FIGURE 3 - Optimal Savings Subsidies.

As in case of the pension policy, the government must rule out "secret borrowing" in order to render the savings subsidy policy effective; hence the remarks made at the end of the preceding sections apply again. The second-best optimum could also be supported if one substituted the numbers $t\left(y^{h}\right)$ for $B\left(y^{h}\right)$ in formula (5). The result is a "pension scheme" with decreasing contributions which, of course, contradict the very notion of social security. Abstracting from institutions, savings subsidies and social security are analytically similar: There exists a multitude of time consistent policies restricting individual freedom in such a way as to preserve the 
second-best, proposition 3 characterizing the point-wise minimum of such interferences, and proposition 3 characterizing the point-wise maximum.

\section{CONCLUSION}

Rational prodigality places additional restrictions on redistributive policies. A society which guarantees a subsistence level to everybody in need - even if the need was self-induced must take into account strategic behavior rendering the accustomed policies time inconsistent. The present paper has analyzed this problem in a second-best framework. It seems convenient to summarize its main findings.

The first result states that in order to rule out prodigality as a rational strategy, the government does not need additional instruments - the usual wage tax suffices perfectly. This has a simple intuition: In the standard model, the self-selection constraints limit the possible degree of redistribution. Rational prodigality introduces an additional limit, so that policies which aim at eliminating rational prodigals must only reduce the degree of redistribution.

Second-best optima can be reached using an additional instrument, namely, savings subsidies. These subsidies are decreasing in income. Typically, they go to the working poor only, leaving the rich unaffected, and thus present a solution which minimizes administrative costs and maximizes individual freedom. By contrast, social security contributions, which also preserve the second-best, are increasing in income, at least up to some ceiling. This suggests that real pension systems do not aim at alleviating the rational prodigality problem and cannot be justified invoking this argument. In fact, one is inclined to think that Hayek, when understanding the above theory, would reject both social security and savings subsidies, because these instruments do not entail a Pareto-improvement but only facilitate more redistribution. Of course, other possible justifications of social security systems, such as myopia or redistributive concerns, have not been considered above, the basic claim being that rational prodigality alone gives no sufficient reason to erect a public pension scheme.

Evaluating the model, a number of restrictive assumptions had to be made. Some propositions rest on the premise that second-period consumption is a normal good. In an aggregate model, such an assumption appears innocuous and does not preclude a preference for present over future consumption; it only states that after an increase in exogenous income, a young person wishes to consume more both today and tomorrow. Assuming time-separable preferences is a more delicate issue. It is equivalent to the premise that distorting intertemporal choices along an indifference curve leaves the propensity to work unaffected. However, since the influence can go in either direction, this may also appear acceptable. The truly critical assumption is the fixed interest factor. With a stochastic interest factor, capital income taxation would become optimal even in the case of time-separable preferences, because the capital income tax acted as an insurance device (Varian 1980). As this presents an intertemporal distortion, the secondbest optimum has a structure differing from that above. If the government has difficulty in observing $R$ and $s$ separately, interest risk would also reinforce the plausibility of why older persons should be given a basic allowance. Perhaps future research can characterize optimal policies in such an extended setting. 


\section{APPENDIX}

As indicated in the text, problem (1) deviates from the standard problem in that there are three commodities rather than two. Thus, the single crossing property (or agent monotonicity), on which most standard proofs rest, has no obvious meaning. But the time separability assumption makes it possible to prove the following:

Generalized Agent Monotonicity (GAM): Consider two triples $\left(c_{1}, c_{2}, y\right)$ and $\left(c_{1}^{h}, c_{2}^{h}, y^{h}\right)$, where $y>y^{h}$, such that person $\mathrm{h}$ is indifferent between them. Then everyone with a higher wage rate strictly prefers the first triple, and everyone with a lower wage rate strictly prefers the second.

Proof: Define the function $\Phi(w)=u\left(c_{1}, c_{2}\right)+v(y / w)-u\left(c_{1}^{h}, c_{2}^{h}\right)-v\left(y^{h} / w\right)$. By hypothesis, we have $\Phi\left(w^{h}\right)=0$. The derivative equals the difference of the marginal disutilities of work

$$
\Phi^{\prime}(w)=v^{\prime}\left(y^{h} / w^{2}\right)-v^{\prime}\left(y / w^{2}\right)>0,
$$

the sign following from our assumptions $v^{\prime}<0, v^{\prime \prime}<0$ and $y^{h}>h$. Hence, everyone with a higher wage rate derives more utility from the first triple, and vice versa.

The intuition behind GAM is simple: Persons with high wage rates find it easier to produce high incomes. Now, production efficiency obtains immediately:

LEMMA: All solutions of (1) are production efficient.

PROOF: Assume there were a budget surplus. If $y^{H}$ equals maximum income feasible for person $H$, it does not belong to any other person's consumption set, so that mimicking presents no problem and person $H$ can be made better off by giving the surplus to him, which presents a Pareto-improvement and disproves optimality of the original allocation.

If $y^{H}$ falls short of maximum feasible income, there exists a number $y>y^{H}$ and a triple $\left(c_{1}, c_{2}, y\right)$ such that person $H$ 's utility remains unchanged and such that there is still a budget surplus. GAM implies that every other person will prefer his own triple strictly to $\left(c_{1}, c_{2}, y\right)$. Hence, we can again make person $H$ better off, using some of the remaining budget surplus.

If these increases in person $H$ 's consumption are carried out in accordance with (3), the proof goes through irrespective of the incentive compatibility constraint. Hence, production efficiency holds in the model of section 3, too, a fact which was used in the proof of proposition 1.

\section{REFERENCES}

Coate, S. (1995) Altruism, the Samaritan's Dilemma, and Government Transfer Policy. American Economic Review 85, pp. 46-57.

Diamond, P. A. (2003) Taxation, Incomplete Markets, and Social Security. Cambridge: MIT Press.

Hayek, F. A. (1960) The Constitution of Liberty. London: Routledge \& Kegan Paul.

Homburg, St. (2000) Compulsory Savings in the Welfare State. Journal of Public Economics 77, pp. 233-239. 
Homburg, St. (2001) The Optimal Income Tax: Restatement and Extensions. FinanzArchiv 58, pp. 363-395.

Konrad, K. A. and G. Wagner (2000) Reform of the Public Pension System in Germany. DIW Discussion paper no. 200, Berlin.

Lindbeck, A. and J. W. Weibull (1988) Altruism and Time Consistency: The Economics of Fait Accompli. Journal of Political Economy 96, pp. 1165-1182.

Matthews, S. and J. Moore (1987) Monopoly Provision of Quality and Warranties: An Exploration in the Theory of Multidimensional Screening. Econometrica 55, pp. 441-467.

Mulligan, C. B. and X. Sala-i-Martin (1999) Social Security in Theory and Practice (II): Efficiency Theories, Narrative Theories, and Implications for Reform. NBER Working Paper no. 7119.

Varian, H. R. (1980) Redistributive taxation as social insurance. Journal of Public Economics. 14, pp. 49-68.

Weizsäcker, J. von (2003) The Hayek Pension. An Efficient Minimum Pension to Complement the Welfare State. CESifo Working paper no. 1064, Munich. 